\title{
Cardiovascular fitness and thermoregulation during prolonged exercise in man
}

\author{
P.L. Greenhaff, BSc, PhD \\ Department of Environmental and Occupational Medicine, University Medical School, Aberdeen, Scotland
}

\begin{abstract}
Summary
Nine healthy male subjects differing in their training status $\left(\mathrm{VOO}_{2} \max 54 \pm 7 \mathrm{ml} \cdot \mathrm{min}^{-1} \cdot \mathrm{kg}^{-1}\right.$, mean $\pm S D ; 43-64 \mathrm{ml} \cdot \mathrm{min}^{-1}$ $\mathrm{kg}^{-1}$, range) exercised on two occasions separated by one week. On each occasion, having fasted overnight, subjects exercised for $1 \mathrm{~h}$ on an electrically braked cycle ergometer at a workload equivalent to 70 per cent $\mathrm{VO}_{2}$ max (test A) or at a fixed workload of $140 \mathrm{~W}$ (test B). Each test was assigned in a randomized manner and was performed at an ambient temperature of $22.5 \pm 0.0^{\circ} \mathrm{C}$ and a relative humidity of $85 \pm 0$ per cent. Absolute exercise workload was the most successful predictor of sweat loss during test $A(r=0.82$, $\mathrm{p}<0.01$ ). Sweat loss was also related to $\dot{\mathrm{VO}}_{2}$ max tests $A(r=0.67, p<0.05)$ and $B(r=0.67, p<0.05)$. There was no relationship between resting pre-exercise core temperature and $\mathrm{VO}_{2}$ max. However, core temperature recorded during the final min of exercise in test $B$ was inversely related to $\dot{\mathrm{VO}} \mathrm{O}_{2} \max (\mathrm{r}=-\mathbf{0 . 8 6}, \mathrm{p}<0.01)$. As a consequence, core temperature during the final minute of exercise was also related to the relative exercise intensity $\left(\% \dot{\mathrm{VO}}_{2}\right.$ max) performed $(\mathrm{r}=0.82, \mathrm{p}<0.01)$. The heart rate response during test $\mathrm{B}$ was inversely related to $\dot{\mathrm{VO}}_{2} \max (\mathrm{r}=-0.71, \mathrm{p}<0.05)$ and was positively related to the relative exercise intensity performed $(r=0.68, p<0.05)$. No relationship was found between weighted mean skin temperature during the final minute of exercise and the relative $(r=0.26)$ or absolute $(r=0.03)$ workloads performed during exercise. The results of the present experiment suggest that cardiovascular fitness ( as indicated by $\mathrm{VO}_{2}$ max) will have a significant influence upon the thermoregulatory responses of Man during exercise.
\end{abstract}

Keywords: Thermoregulation, sweat loss, $\mathrm{vO}_{2} \max$, exercise

\section{Introduction}

It has been generally accepted that physical training will to some extent precondition Man to exercise in the heat by improving heat dissipating function (heat acclimatization). Piwonka et al. indicated that the strenuous daily exercise performed by competitive

Address for correspondence: Dr P L Greenhaff, PhD, Department of Comparative Physiology, The Animal Health Trust, Balaton Lodge, Snailwell Road, Newmarket, Suffolk CB8 7DW, UK

(C) 1989 Butterworth \& Co (Publishers) Ltd 0306-3674/89/020109-06\$03.00 distance runners will result in total heat acclimatization and may be used as an effective method of preconditioning men to work in the heat ${ }^{1}$. Strydom and Williams demonstrated that a less severe training programme will improve heat tolerance, but will not completely acclimatize individuals to work in the heat ${ }^{2}$.

Several authors have suggested that the condition of heat acclimatization seen in highly trained individuals may possibly be the result of the repeated hyperthermia experienced by such individuals during their daily training session ${ }^{3-5}$. Furthermore, Henane et al. postulated that repeated exercise-induced hyperthermia will result in trained individuals becoming more responsive to core temperature changes (heat adaption) ${ }^{6}$. However, it has also been proposed that improvements in heat dissipating function may be the direct result of an exercise-induced alteration in cardiovascular function thereby allowing a greater volume of blood to perfuse the skin of the trained individual at any fixed submaximal workload ${ }^{5}$.

Few studies have attempted to differentiate between the separate influences of heat acclimatization and cardiovascular adaptation on heat dissipation during exercise. Schvartz et al. concluded that improvements in heat dissipating function arising from a period of physical training in the heat are largely the result of heat adaptation? However, because the intensity of daily training performed by subjects in that study was very low $(41 \mathrm{~W})$, the contribution made by an improvement in cardiovascular function to heat dissipation was not adequately assessed.

The present experiment was therefore undertaken to re-examine the proposal of Schvartz et al. that heat adaptation will be the dominant factor influencing Man's thermoregulatory responses during exercise at moderate temperatures?.

\section{Methods}

Nine healthy male volunteers were pre-selected to take part in the experiment on the basis of their training status and aerobic capacity $\left(\mathrm{VO}_{2}\right.$ max). Subjects ranged from untrained but recreationally active $\left(\mathrm{VO}_{2}\right.$ max $\left.40-45 \mathrm{ml} \cdot \mathrm{min}^{-1} \cdot \mathrm{kg}^{-1}\right)$ to well trained $\left(\mathrm{VO}_{2} \max 60-\right.$ $\left.65 \mathrm{ml} . \mathrm{min}^{-1} \cdot \mathrm{kg}^{-1}\right)$. However, none of the subjects was highly trained $\left(\mathrm{VO}_{2} \max >65 \mathrm{ml} \cdot \mathrm{min}^{-1} \cdot \mathrm{kg}^{-1}\right.$, Table 1$)$. 
The experiment was undertaken within an environmentally controlled climatic chamber between the months of February and March.

Prior to commencing the experiment, $\mathrm{VO}_{2}$ max was measured in all subjects during a discontinuous stepwise test with the use of a semi-automated on-line gas analysis system (Gould 9000 IV Computerized Pulmonary Exercise Lab, Cardiokinetics, Salford, UK). Each $\mathrm{VO}_{2}$ max test and all subsequent exercise tests were performed on an electrically-braked cycle ergometer (Siemens EM 840, Siemens Ltd, Sunbury-on-Thames, $\mathrm{UK})$. At least four days after the determination of $\mathrm{VO}_{2}$ max subjects performed a $1 \mathrm{~h}$ 'trial test' at a workload calculated to be equivalent to 70 per cent $\mathrm{VO}_{2}$ max. The purpose of this test was to confirm that pre-determined workload was equal to 70 per cent $\dot{V^{\prime}}{ }_{2}$ max and also to ensure that the exercise intensity could be sustained for a $1 \mathrm{~h}$ period.

Following a one week 'recovery period' subjects reported to the laboratory on two further occasions, separated by one week. On each occasion, having fasted overnight, subjects either exercised for $1 \mathrm{~h}$ at a workload equal to 70 per cent $\mathrm{VO}_{2} \max$ (test $\mathrm{A}$ ) or for $1 \mathrm{~h}$ at a fixed workload of $140 \mathrm{~W}$ (test B). Each test was assigned in a randomized manner. The experimental protocol was designed with the prior knowledge that the sweating response of Man during exercise is closely related to the absolute workload performed, while the core and skin temperature responses are more related to the relative workload performed ${ }^{8}$. Each test was assigned in a randomized manner and was performed at an ambient temperature of $22.5 \pm 0.0^{\circ} \mathrm{C}$ and relative humidity of $85 \pm 0$ per cent.

Prior to both tests nude body weight was recorded, a rectal temperature probe (Clandon Southern, Aldershot, UK) was inserted to a depth of $14 \mathrm{~cm}$ beyond the external anal sphincter, and a three lead ECG (Consolidated Medical Equipment, New York, USA) and four temperature probes (Comark Electronics, Rustington, UK) were fixed to the skin. Skin temperature was measured at the four sites of mid-dorsal upper arm, lateral chest, mid-thigh and mid-calf with the use of a digital microprocessor thermometer (Comark Electronics, Rustington, UK) and the values obtained were used to calculate weighted mean skin temperature according to the method described by Mitchell and Wyndham. ${ }^{9}$

For the $10 \mathrm{~min}$ immediately prior to each exercise test, subjects sat at rest on the cycle ergometer. During this time period and the following exercise test, recordings of relative humidity, heart rate and skin, rectal and room temperature were made every $5 \mathrm{~min}$. Heart rate was measured using a medical heart rate monitor (Kontron Instruments Ltd., St Albans, UK), relative humidity using a hair hygrometer (Gallenkamp, Loughborough, UK) and room and rectal temperature using a YSI Tele thermometer (Clandon Southern, Aldershot, UK). In addition, a 2 min gas sample was collected every 15 min during each exercise test using the Douglas bag method. Each expired gas sample was used to determine carbon dioxide (Beckman LB-2 $\mathrm{CO}_{2}$ analyser, Beckman-RIIC Ltd., High Wycombe, UK) and oxygen (Servomex $\mathrm{O}_{2}$ analyser, Servomex Ltd., Crowborough, UK) content, gas volume (Harvard digital dry gas meter, Harvard Apparatus Ltd., Edenbridge, UK) and gas temperature (Comark digital microprocessor thermometer, Comark Electronics, Rustington, UK). The values obtained were used to calculate oxygen consumption during exercise.

Upon completion of the exercise task, skin and rectal temperature probes were removed. Subjects then showered and after the removal of surface water, nude body weight was again recorded. Water lost as sweat was estimated after correction for respiratory weight $\operatorname{loss}^{10}$.

Statistical analysis involved the use of bivariate linear regression and the determination of the Pearson correlation coefficient (Minitab statistical package, Pennsylvania State University, USA). Values shown in the text are presented as mean $\pm S D$; in the figures as mean $\pm S E$. On occasion, in an effort to demonstrate the population distribution mean, $\mathrm{SD}$ and range are presented in the text.

This study was approved by the local Ethics Committee.

\section{Results}

\section{Physical characteristics}

The physical characteristics of subjects involved in the present experiment are shown in Table 1. Maximal oxygen uptake $\left(\mathrm{VO}_{2}\right.$ max) covered a wide range (43-64 ml.min ${ }^{-1} \cdot \mathrm{kg}^{-1}$ ) and was not related to body height $(r=0.46)$, body weight $(r=0.60)$, body surface area $(r=0.63)$ or age $(r=-0.43)$. In test $A$, subjects exercised at a workload of $193 \pm 34 \mathrm{~W}$ (mean $\pm S D$; range 140 $235 \mathrm{~W})$. This was equivalent to $70 \pm 4$ per cent $\mathrm{VO}_{2}$ max (range 66-75 per cent $\mathrm{VO}_{2}$ max). In test $\mathrm{B}$, workload was fixed at $140 \mathrm{~W}$. In relative terms this was equal to $50 \pm 13$ per cent $\mathrm{VO}_{2}$ max (range $35-68$ per cent $\mathrm{VO}_{2}$ max). The absolute workload performed in test $\mathrm{A}$ was related to body weight $(\mathrm{r}=0.78, \mathrm{p}<0.05)$, body surface area $(\mathrm{r}=0.83, \mathrm{p}<0.01)$ and $\mathrm{VO}_{2} \max (\mathrm{r}=0.94$, $p<0.001)$. In test $B$, as expected, the relative exercise intensity at which exercise was performed (per cent $\mathrm{VO}_{2}$ max) was inversely related to body weight $(\mathrm{r}=0.68, \mathrm{p}<0.05)$, body surface area $(\mathrm{r}=-0.72$, $\mathrm{p}<0.05)$ and $\mathrm{VO}_{2} \max (\mathrm{r}=-0.95, \mathrm{p}<0.001)$.

\section{Sweating responses}

Sweat loss in test A $(932 \pm 383 \mathrm{~g}$; range $341-1410 \mathrm{~g})$ was equal to $1.3 \pm 0.5$ per cent of pre-exercise body weight and was related to body weight $(r=0.82, p<0.01)$,

Table 1. Physical characteristics of subjects $(n=9)$

\begin{tabular}{|c|c|c|c|c|c|}
\hline $\begin{array}{l}\text { Mean } \\
\text { SD } \\
\text { Range }\end{array}$ & $\begin{array}{c}\text { Age } \\
\text { (yr) } \\
28 \\
6 \\
20-40\end{array}$ & $\begin{array}{c}\text { Height } \\
\text { (cm) } \\
178 \\
3 \\
174-182\end{array}$ & $\begin{array}{c}\text { Weight } \\
\text { (kg) } \\
68.5 \\
5.8 \\
60.7-78.9\end{array}$ & $\begin{array}{c}\text { Surface Area } \\
\left(\mathrm{m}^{2}\right) \\
1.84 \\
0.08 \\
1.75-1.97\end{array}$ & $\begin{array}{c}\mathrm{VO}_{2} \max \\
\left(\mathrm{ml}^{-m_{i n}^{-1}} \cdot \mathrm{kg}^{-1}\right) \\
54 \\
7 \\
43-64\end{array}$ \\
\hline
\end{tabular}


Thermoregulation during exercise: P.L. Greenhaff

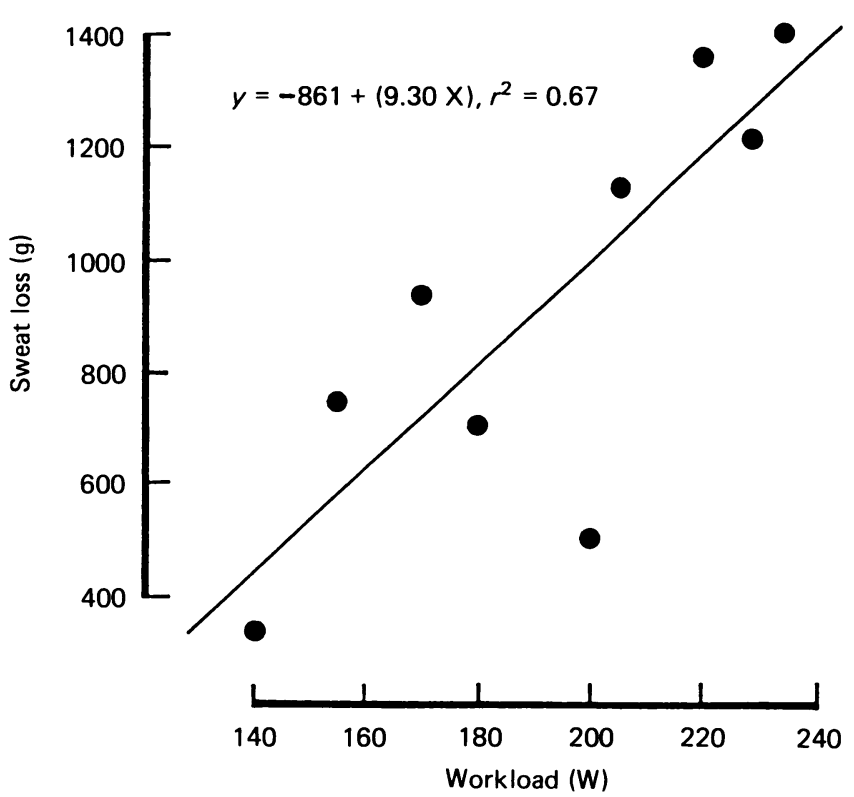

Figure 1. Relationship between absolute workload performed and absolute sweat loss during test $\mathrm{A}$. Measurements were made on 9 male subjects who exercised for $1 \mathrm{~h}$ on an electrically braked cycle ergometer at 70 per cent $\mathrm{VO}_{2}$ max.

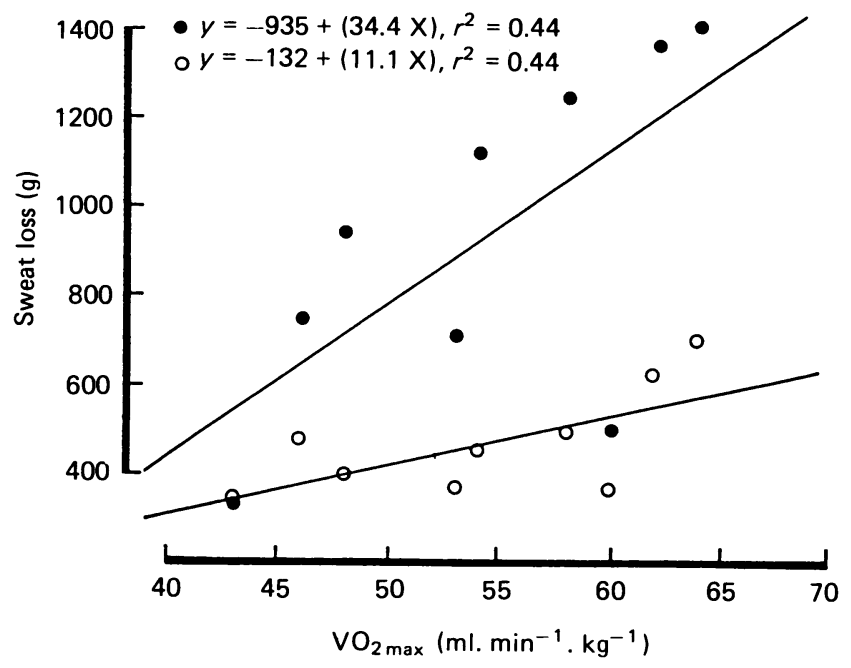

Figure 2. Relationship between maximal oxygen uptake $\left(\mathrm{VO}_{2}\right.$ max) and absolute sweat loss during test $\mathrm{A}(\mathrm{O})$ and test $\mathrm{B}(\mathrm{O})$. Measurements were made on 9 male subjects who exercised for $1 \mathrm{~h}$ on electrically braked cycle ergometer at 70 per cent $\mathrm{VO}_{2}$ $\max$ (test A) and $140 \mathrm{~W}$ (test B).

body surface area $(\mathrm{r}=0.85, \mathrm{p}<0.01)$, absolute exercise workload $(\mathrm{r}=0.82, \mathrm{p}<0.01$ Figure 1$)$ and $\mathrm{VO}_{2}$ max $(\mathrm{r}=0.67, \mathrm{p}<0.05$ Figure 2). Sweat loss in test $\mathrm{b}$ ( $468 \pm 123 \mathrm{~g}$; range $349-702 \mathrm{~g}$ ) was equal to $0.7 \pm 0.1$ per cent of pre-exercise body weight and was related only to $\mathrm{VO}_{2} \max (\mathrm{r}=0.67, \mathrm{p}<0.05$ Figure 2).

Rectal temperature responses

Rectal temperature increased gradually throughout exercise in test $\mathrm{B}$ (Figure 3), rising from $37.0 \pm 0.4^{\circ} \mathrm{C}$ immediately prior to exercise to $38.2 \pm 0.3^{\circ} \mathrm{C}$ during the final min of exercise. During test A there was no increase in rectal temperature until after $5 \mathrm{~min}$ of exercise when values were seen to increase from $37.1 \pm 0.2^{\circ} \mathrm{C}$ to $39.0 \pm 0.5^{\circ} \mathrm{C}$ recorded during the final min of exercise. As expected, the rise in rectal temperature during test $A$ was more marked than the rise recorded in test $B$. In tests $A$ and $B$ resting pre-exercise rectal temperature was not related to $\mathrm{VO}_{2}$ max $(\mathrm{r}=0.01, \mathrm{r}=-0.10$ respectively).

However, rectal temperature during the final minute of exercise in test $\mathrm{B}$ was inversely related to $\mathrm{VO}_{2} \max$ $(\mathrm{r}=-0.86, \mathrm{p}<0.01$ Figure 4$)$ and was positively related to the relative exercise intensity (per cent $\mathrm{VO}_{2}$ max) at which exercise was performed $(\mathrm{r}=0.82, \mathrm{p}<0.01$ Figure 4). This was not the case in Test $A(r=0.43, r=-0.46$ respectively); rectal temperature recorded during the final minute of exercise was related only to resting preexercise heart rate $(r=0.72, p<0.05)$. Rectal temperature recorded during the final minute of exercise in test $B$ was not related to pre-exercise heart rate $(r=0.27)$ but was related to heart rate recorded at the same point $(\mathrm{r}=0.71, \mathrm{p}<0.05$ Figure $5 A)$. In addition, the change in rectal temperature during exercise in test $B$ was related
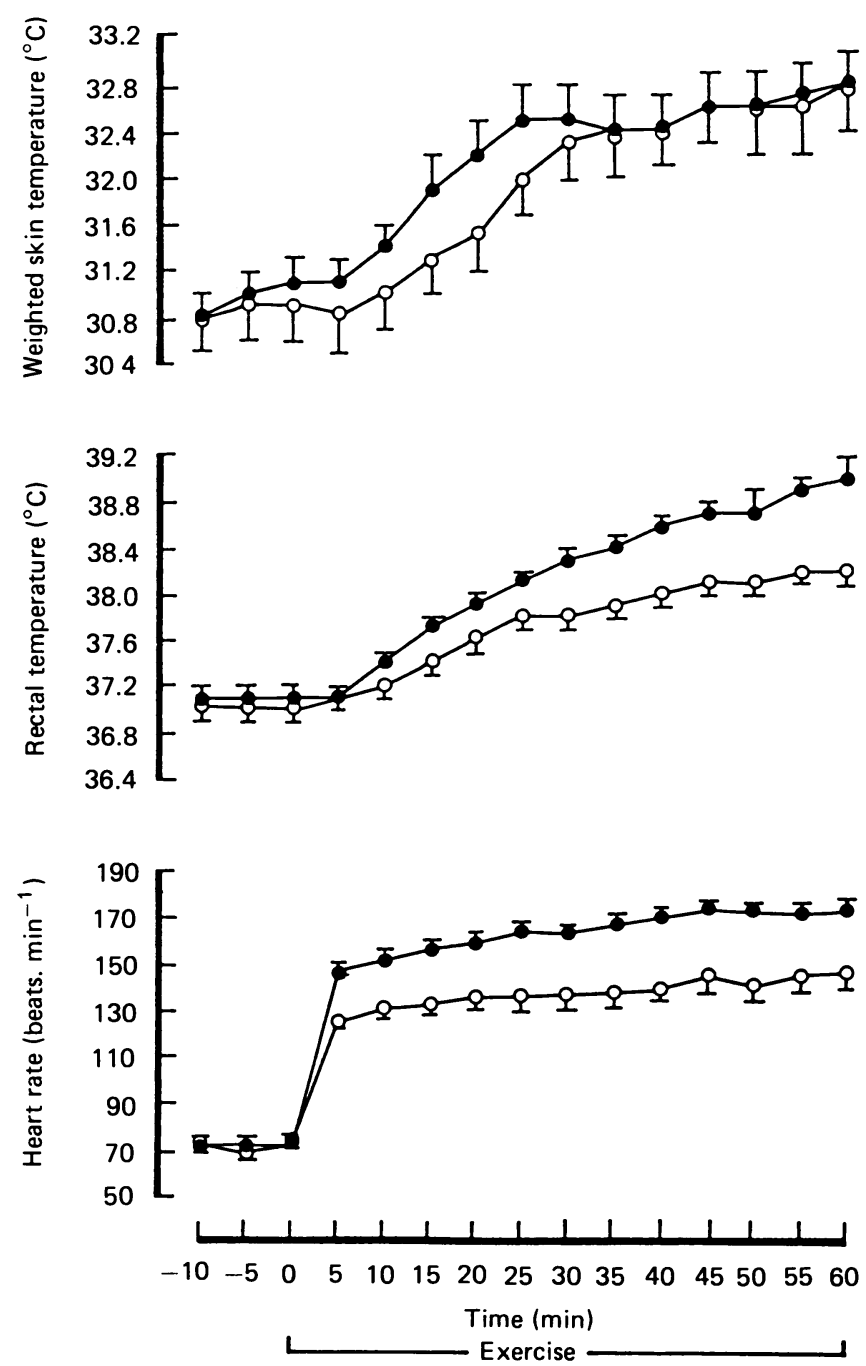

Figure 3. Weighted mean skin temperature, rectal temperature and heart rate measured every $5 \mathrm{~min}$ for the $10 \mathrm{~min}$ rest period prior to exercise and for the whole of the exercise period at 70 per cent $\mathrm{VO}_{2} \max (O)$ and $140 \mathrm{~W}(\mathrm{O})$. Values represent mean $\pm \mathrm{SE}$ 


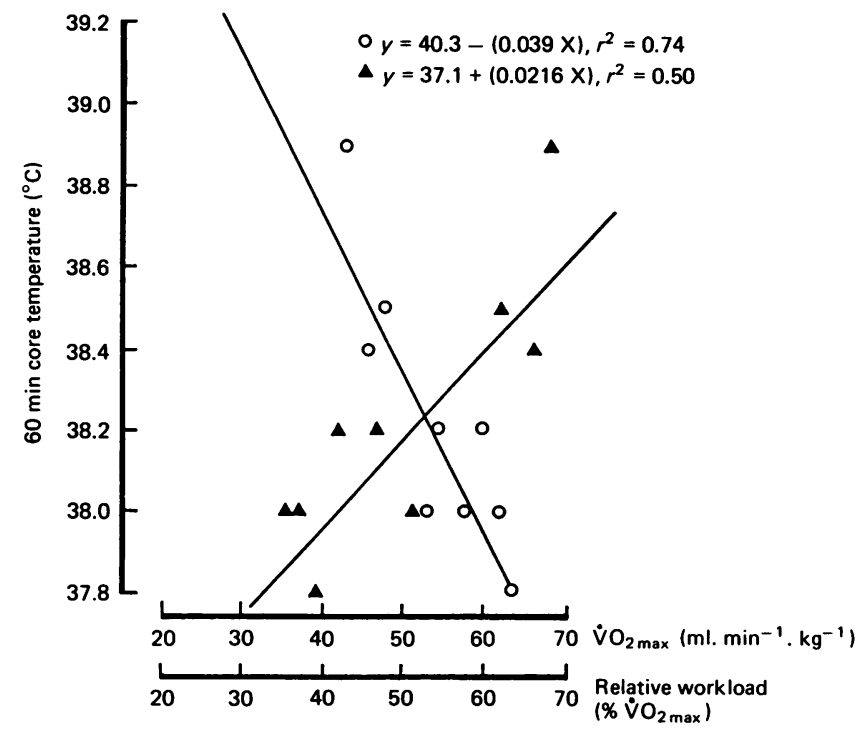

Figure 4. Relationships between maximal oxygen uptake $\left(\mathrm{VO}_{2}\right)$ max) and $60 \mathrm{~min}$ exercise core temperature $(O)$ and relative exercise workload (per cent $\mathrm{VO}_{2}$ max) and 60 min exercise core temperature $(\boldsymbol{\Delta})$. Measurements were made on 9 male subjects who exercised for $1 \mathrm{~h}$ on an electrically braked cycle ergometer at $140 \mathrm{~W}$ (test B).

to heart rate recorded during the final minute of exercise $(r=0.89, p<0.01$ Figure $5 B)$ and the change in heart rate during exercise $(r=0.66, p<0.05$ Figure $5 B)$.

\section{Heart rate responses}

Heart rate increased rapidly with the onset of exercise (Figure 1), reaching values of $147 \pm 10$ beats. $\min ^{-1}$ and $125 \pm 9$ beats. min $^{-1}$ after 5 min of exercise in tests $A$ and $B$ respectively. During the remaining $55 \mathrm{~min}$ of exercise, heart rate increased slowly at approximately the same rate during each test. Values of $173 \pm 14$ beats. $\mathrm{min}^{-1}$ and $145 \pm 21$ beats. $\mathrm{min}^{-1}$ were recorded during the final minute of exercise tests $A$ and $B$ respectively. There was no relationship between preexercise heart rate and $\mathrm{VO}_{2}$ max in tests $\mathrm{A}(\mathrm{r}=0.01)$ or $B(r=0.02)$. However, heart rate recorded during the final minute of exercise in test $B$ was inversely related to body weight $(\mathrm{r}=-0.78, \mathrm{p}<0.05)$, body surface area $(\mathrm{r}=-0.72, \mathrm{p}<0.05)$, absolute sweat loss $(\mathrm{r}=0.67$, $\mathrm{p}<0.05)$, and $\mathrm{VO}_{2} \max (\mathrm{r}=-0.71, \mathrm{p}<0.05)$ and was positively related to the relative exercise intensity $(r=0.68, p<0.05)$. Similar relationships were not found in test $\mathrm{A}(\mathrm{r}=-0.42, \mathrm{r}=-0.23, \mathrm{r}=-0.02, \mathrm{r}=0.37$, $\mathrm{r}=-0.19$ respectively)

\section{Skin temperature responses}

During both tests mean skin temperature did not increase until after 5 min of exercise. In test $A$ values increased from $31.1 \pm 0.6^{\circ} \mathrm{C}$ to $32.5 \pm 1.0^{\circ} \mathrm{C}$, recorded after $25 \mathrm{~min}$ of exercise (Figure 3 ). Throughout the remainder of test $A$, skin temperature was relatively stable, reaching $32.8 \pm 1^{\circ} \mathrm{C}$ during the final minute of exercise. In test $\mathrm{B}$, skin temperature increased from $30.8 \pm 0.9^{\circ} \mathrm{C}$ to $32.4 \pm 1.1^{\circ} \mathrm{C}$, recorded after $35 \mathrm{~min}$ of exercise. From this point onwards the change in skin temperature was relatively small and closely matched the pattern of change recorded in test $\mathrm{A}$ (Figure 3).

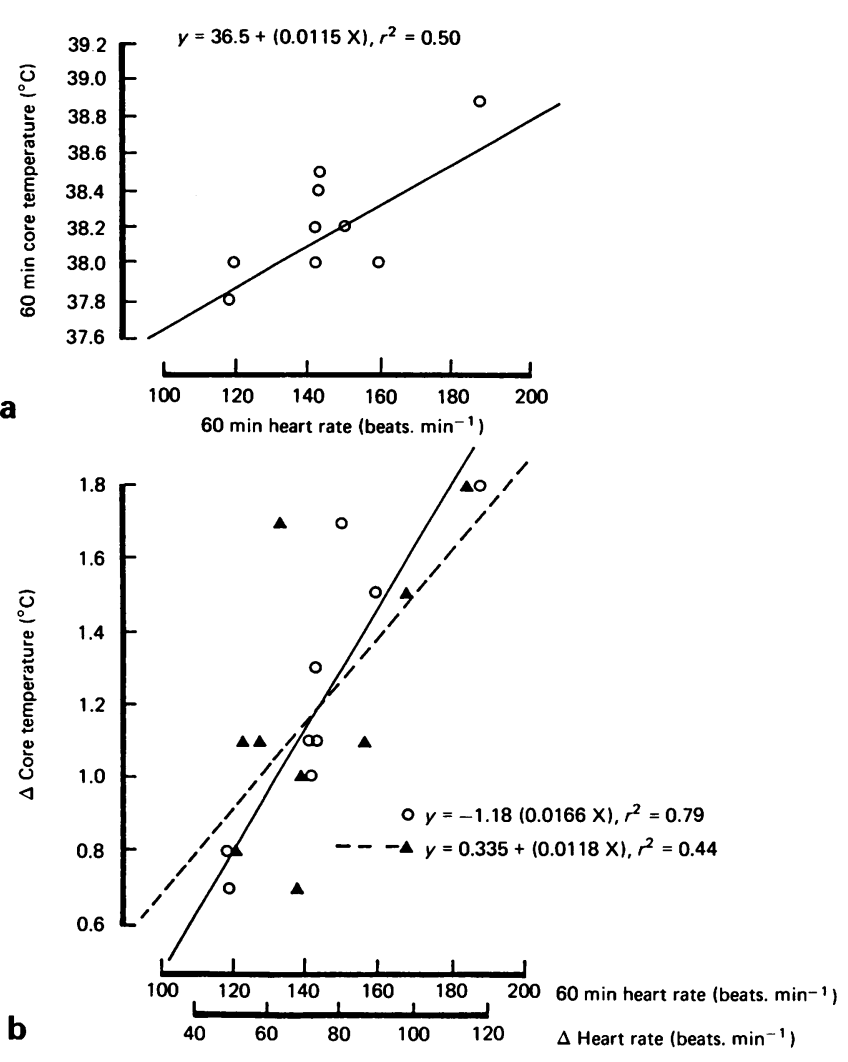

Figure 5. $a$ : Relationship between $60 \mathrm{~min}$ exercise heart rate and 60 min core temperature

$b$ : Relationships between $60 \mathrm{~min}$ exercise heart rate and the change in core temperature during exercise $(\mathrm{O})$ and the change in heart rate during exercise and the change in core temperature during exercise $(\boldsymbol{\Delta})$

All measurements were made on 9 male subjects who exercised for $1 \mathrm{~h}$ on an electrically braked cycle ergometer at $140 \mathrm{~W}$ (test B).

In both tests there was no relationship between skin temperature (the value recorded at rest prior to exercise, the change recorded during exercise and the value recorded during the final minute of exercise) and $\dot{\mathrm{VO}}_{2}$ max, absolute workload or the corresponding core temperature responses (Table 2). Perhaps surprisingly, in test $B$, there was no relationship between the skin temperature responses and the relative exercise intensity performed (Table 2).

\section{Discussion}

The results of the present experiment indicate that cardiovascular fitness (as indicated by $\mathrm{VO}_{2}$ max) will play a major role in determining the thermoregulatory response of Man during exercise at a mild ambient temperature. This is contrary to the suggestion of Schvartz et al. that the thermoregulatory responses of Man are mainly a function of heat adaptation ${ }^{7}$.

Sweat loss and $\mathrm{VO}_{2}$ max

In agreement with Saltin and Hermansen, the results of test $\mathrm{A}$ indicate that sweat loss in Man is greatly dependent upon the absolute workload performed during exercise $(\mathrm{r}=0.82, \mathrm{p}<0.01 \text {, Figure } 1)^{8}$. However, it is also clear from the results of tests A and B that 
Table 2. Values indicating the degree of association between mean skin temperature and $\mathrm{VO}_{2}$ max, absolute workload, core temperature and relative exercise intensity in tests $A$ and $B$. Values shown represent the Pearson Correlation coefficient. At no point was statistical significance attained $(n=9)$.

\begin{tabular}{|c|c|c|c|c|c|c|}
\hline & \multicolumn{2}{|c|}{ Pre-exercise } & \multicolumn{4}{|c|}{ Mean skin temperature $\left({ }^{\circ} \mathrm{C}\right)$} \\
\hline & TestA & Test $B$ & Test $A$ & Test $B$ & Test $A$ & Test $B$ \\
\hline$\dot{\mathrm{VO}}_{2} \max \left(\mathrm{ml} \cdot \mathrm{min}^{-1} \cdot \mathrm{kg}^{-1}\right)$ & -0.18 & -0.17 & 0.00 & -0.37 & 0.18 & -0.19 \\
\hline Absolute workload performed (W) & -0.01 & - & 0.03 & - & 0.07 & - \\
\hline Pre-exercise core temperature $\left({ }^{\circ} \mathrm{C}\right)$ & 0.50 & 0.32 & 0.38 & -0.49 & 0.12 & -0.57 \\
\hline Final minute exercise core & & & & & & \\
\hline temperature $\left({ }^{\circ} \mathrm{C}\right)$ & 0.54 & 0.34 & 0.46 & 0.02 & 0.19 & -0.19 \\
\hline Change in core temperature $\left({ }^{\circ} \mathrm{C}\right)$ & 0.23 & 0.02 & 0.22 & 0.45 & 0.12 & 0.34 \\
\hline Relative workload performed ( $\% \mathrm{VO}_{2}$ max) & - & 0.20 & - & 0.26 & - & 0.08 \\
\hline
\end{tabular}

cardiovascular fitness (as indicated by $\mathrm{VO}_{2}$ max) will significantly influence the degree of sweat loss during exercise $(r=0.67, p<0.05 ; r=0.67, p<0.05$ respectively, Figure 2). The relationship between cardiovascular fitness and sweat loss in Man during exercise has been previously reported ${ }^{3,6,11,12}$. However, it is important to note that in both exercise tests of the present experiment $\mathrm{VO}_{2}$ max only accounted for 45 per cent of the variation in sweat loss during exercise.

As a consequence, it is plausible to suggest that exercise-induced heat adaptation may have also influenced the sweating response. This is supported by the finding of Henane et al. that the sweating response of skiers during passive heating was more marked than that of swimmers, despite $\mathrm{VO}_{2}$ max being similar in both groups ${ }^{6}$. The authors suggested that this finding may have resulted from skiers experiencing a greater degree of exercise induced hyperthermia during exercise and thereby becoming better acclimitized than swimmers.

The results of the present experiment suggest than when exercise is performed at the same absolute workload sweat loss is not related to body weight $(r=0.57)$ or body surface area $(r=0.65)$. This finding indicates that the greater sweat loss observed in fitter individuals during test $B$ was not a result of body weight influencing metabolic rate as has been suggested in the past $^{13}$. The strong relationship between sweat loss and body weight $(\mathrm{r}=0.82, \mathrm{p}<0.01)$ and body surface area $(\mathrm{r}=0.85, \mathrm{p}<0.01)$ in test A can probably be attributed to the finding that body weight and body surface area are related to exercise workload $(\mathrm{r}=0.78, \mathrm{p}<0.05$; $\mathrm{r}=0.83, \mathrm{p}<0.01$ respectively), which in turn is related to sweat loss $(r=0.82, p<0.01)$.

\section{Core temperature and $\mathrm{VO}_{2}$ max}

The strong relationship between relative exercise intensity and core temperature during the final minute of exercise in tests $B(r=0.82, p<0.01)$ supports the finding of Saltin and Hermansen that rectal temperature during exercise is closely related to the relative workload performed ${ }^{8}$. As would therefore be expected, the results of the present experiment also suggest $\mathrm{VO}_{2}$ max will significantly influence core temperature during exercise; accounting for 74 per cent of the variability in core temperature measured during the final minute of exercise in test $B(r=-0.86, p<0.01$ Figure 4$)$.

A major proposal of Schvartz et al. was that $\mathrm{VO}_{2}$ max will have only a minor influence in determining core temperature in Man during exercise ${ }^{7}$. This proposal was based upon the finding that $\mathrm{VO}_{2}$ max accounted for only 38 per cent of the variation in rectal temperature during exercise. The authors indicated that in situations where skin temperature is greater than ambient temperature, body heat loss will be partially dependent upon the surface area-to-mass ratio of each subject. They went on to suggest that because the surface area-to-mass ratio may be related to $\mathrm{VO}_{2}$ max and exercise core temperature, any relationship between $\mathrm{VO}_{2}$ max and core temperature during exercise may be purely coincidental.

However, the finding that during the present study body surface area and body weight were not related to $\mathrm{VO}_{2} \max (\mathrm{r}=0.63, \mathrm{r}=0.60$ respectively) or rectal temperature during the final minute of exercise in test $B$ $(r=0.65, r=0.64$ respectively) is not in accordance with the above suggestion. The lack of agreement between the results of the present experiment and those of Schvartz et al. is probably related to the low exercise workload performed by subjects during the latter experiment (41 and $82 \mathrm{~W}$ ), resulting in rectal temperature rarely increasing above $38^{\circ} \mathrm{C}$.

$\mathrm{VO}_{2}$ max has been suggested in the past to influence resting core temperature. Baum et al. reported lower resting core temperatures in male long distance runners ${ }^{3}$. Drinkwater et al. reported a similar response in female athletes ${ }^{14}$. Henane $e t$ al. showed a decrease in resting core temperature after a period of endurance training ${ }^{6}$. However, Schvartz indicated that resting rectal temperature is more a function of the degree of heat adaptation than $\mathrm{VO}_{2}$ max ${ }^{7,15,16}$. The finding in the present study that there was no relationship between $\mathrm{VO}_{2}$ max and resting core temperature in test $\mathrm{A}$ $(r=-0.13)$ or test $B(r=-0.10)$ perhaps supports this latter proposal.

\section{Heart rate and $\mathrm{VO}_{2}$ max}

The inverse relationship between final minute heart rate and $\mathrm{VO}_{2}$ max in test $\mathrm{B}(\mathrm{r}=-0.71, \mathrm{p}<0.05)$ indicates that heart rate is more closely related to the relative workload performed than the absolute workload ${ }^{17}$. Gisolfi was the first to propose that because training adaptations result in a reduced muscle blood flow for a given submaximal workload, trained individuals may have a larger volume of blood available to perfuse the skin and thereby dissipate more heat ${ }^{5}$. The close relationship between heart rate responses and core temperature responses during exercise in test $\mathrm{B}$ (Figure 5 ) is possibly in agreement with this suggestion. 


\section{Skin temperature}

The results of the present experiment do not support the proposal that mean skin temperature during exercise is related to the relative workload performed ${ }^{8}$. No relationship was found between skin temperature and the relative $(r=0.26)$ or absolute $(r=0.03)$ workloads performed during exercise. The changes occurring in skin temperature during the first $30 \mathrm{~min}$ of exercise appear to match those of rectal temperature. However, after this time point the pattern of change in skin temperature is difficult to explain. Despite metabolic heat production and core temperature being higher in test $\mathrm{A}$, skin temperature during the final 30 min of both tests was very similar (Figure 3 ). It is not known whether the high relative humidity at which both tests were performed (85 per cent) may have influenced the degree of heat loss from the skin surface. However, it is plausible to suggest that the close similarity in skin temperatures during the second half of both tests may have arisen because sweat was unable to evaporate from the skin surface.

\section{Acknowledgements}

The author wishes to thank Mrs L. Alexander for preparation of the manuscript, Mr R. Summers for excellent technical assistance and Dr R.J. Maughan, Mr J. Leiper and Mr P. Clough for their help at various stages of this work.

\section{References}

1 Piwonka, R.W., Robinson, S., Gray, V.L. and Manatis, R.S., Preacclimatization of men to heat by training $J$ Appl Physiol 1965, 20, 379-384.

2 Strydom, N.B. and Williams, C.G. Effects of physical conditioning on state of heat acclimatization of Bantu laborers J Appl Physiol 1969, 27, 262-265

3 Baum, E., Bruk, K. and Schwennicke H.P. Adaptive modifications in the thermoregulatory system of long distance runners J Appl Physiol 1976, 40, 404-410
4 Gisolfi, C. and Robinson, S. Relations between physical training, acclimatization, and heat tolerance J Appl Physiol 1969, 26, 530-534

5 Gisolfi, C. Work-heat tolerance derived from interval training J Appl Physiol 1973, 35, 349-354

6 Henane, R., Flandrois, R., and Charbonnier, J.P. Increase in sweating sensitivity by endurance conditioning in man J Appl Physiol 1977, 43, 822-828

7 Schvartz, E., Shapiro, Y., Magazanik, A., Meroz, A., Birnfeld, H., Mechtinger, A. and Shibolet, S. Heat acclimation, physical fitness, and responses to exercise in temperature and hot environments J Appl Physiol 1977, 43, 678-683

8 Saltin, B. and Hermansen, L. Esophageal, rectal, and muscle temperature during exercise J Appl Physiol 1966, 21, 1757-1762

9 Mitchell, D. and Wyndham, C.H. Comparison of weighting formulas for calculating mean skin temperature J Appl Physiol 1969, 26, 616-622.

10 Mitchell J.W., Nadel E.R. and Stolwijk J.A.J. Respiratory weight losses during exercise J Appl Physiol 1972, 32, 474-476

11 Piwonka, R.W. and Robinson, S. Acclimatization of highly trained men to work in severe heat J Appl Physiol $1967,22,9-12$

12 Irion, G.L. Responses of distance runners and sprinters to exercise in a hot environment Aviat Space Environ Med 1987, 58, 948-953

13 Strydom, N.B., Wyndham, C.H., Williams, C.G., Morrison, J.F., Bredell, G.A.G., Benade, A.J.S. and VonRahden, M. Acclimatization to humid heat and the role of physical conditioning J Appl Physiol 1966, 21, 636-642

14 Drinkwater, B.L., Denton, J.E., Jupprat, I.C., Talag, T.S. and Horvath S.M. Aerobic power as a factor ion women's response to work in hot environments J Appl Physiol 1976, 41, 815-821

15 Schvartz, E., Saar, E., Meyerstein, N. and Benor, D. A comparison of three methods of acclimatization to dry heat I Appl Physiol 1973, 34, 214-219

16 Schvartz, E., Magazanik, A. and Glick, Z. Thermal responses during training in a temperate climate $J \mathrm{Appl}$ Physiol 1974, 36, 572-577

17 Astrand, P.O. and Rodhal. K. 'Textbook of work physiology' McGraw-Hill, New York, 1977 